\title{
ENVELHECIMENTO ATIVO: NOVAS PERSPECTIVAS E OPORTUNIDADES PARA O CAMPO DO DESIGN EMOCIONAL
}

\author{
Marília Ceccon Salarini da Rosa \\ Pontifícia Universidade Católica do Rio de Janeiro - PUC-Rio \\ mariliaceccon@yahoo.com.br \\ Sílvia Nogueira Jordão \\ Pontifícia Universidade Católica do Rio de Janeiro - PUC-Rio \\ silviapn@gmail.com \\ Vera Maria Marsicano Damazio \\ Pontifícia Universidade Católica do Rio de Janeiro - PUC-Rio \\ vdamzio@puc-rio.br
}

\begin{abstract}
Resumo: A população de todo o planeta está envelhecendo, vivendo cada vez mais e trazendo novos desafio para o design. Este artigo tem como base: (1) as orientações do "Guia Global: Cidade Amiga do Idoso", elaborado pela Organização Mundial da Saúde; (2) estudo sobre vertentes, métodos e referencial teórico do design emocional; e (3) estudo de identificação de demandas e geração de idéias de novos produtos e serviços para o crescente, numeroso e diversificado público idoso. Ele foi estruturado em três seções: a primeira mostra dados sobre o envelhecimento no mundo, a segunda apresenta o "Guia Global: Cidade Amiga do Idoso" e a terceira traz possibilidades de atuação do design em prol do envelhecimento ativo, ilustradas com exemplos. Seu principal objetivo é contribuir com o projeto de uma sociedade idosa próspera, respeitada e com mais opções de viver mais e melhor.
\end{abstract}

Palavras-chave:Design Emocional, Envelhecimento Ativo, Auto estima, Bem estar.

\begin{abstract}
The population of the entire planet is getting older, living a longer life and bringing new challenges for designers. This article is based on: (1) guidelines of the "Global age-friendly cities: a guide", created by the World Health Organization, (2) study of aspects, methods and theoretical references on emotional design, and (3) studies to identify demands and generate ideas for new products and services for the growing, numerous and diverse elderly public. It was structured in three sections: first one shows data on aging in the world, second one presents the "Global age-friendly cities: a guide" and the third one brings design possibilities to support acitve aging, illustrated with examples. Its main goal is to contribute to the project of a successful aging society, more respected, with more options to live longer and better.
\end{abstract}

Keywords: Emotional Design, Active aging, Self esteem, Well being. 


\section{INTRODUÇÃO}

O envelhecimento populacional é hoje um fenômeno global sem precedentes. A proporção de pessoas idosas aumenta mais rapidamente do que qualquer outra faixa etária em um número cada vez maior de países e estima-se que em 2050 haverá mais idosos do que crianças no mundo. Em menos de quatro décadas, seremos dois bilhões de pessoas com mais de 60 anos, representando $30 \%$ da população mundial (OMS, 2007).

O envelhecimento populacional é uma conquista da humanidade, mas sem dúvida, uma nova e surpreendente realidade (UNFPA e HAI, 2012). Ela mudará a forma de entender os ganhos e perdas da velhice; de viver e ver a aposentadoria; de manter a produtividade e o engajamento social, de criar e fortalecer vínculos afetivos e a interação entre gerações; de buscar a plenitude e, consequentemente, de atender a contento as demandas da crescente população dos maiores de 60 anos que agora vivem cada vez mais tempo.

A longevidade também é uma conquista da humanidade e realidade igualmente nova e surpreendente. "Vamos viver 30 anos mais do que nossos avós", alerta o ex-diretor do Departamento de Envelhecimento e Saúde da Organização Mundial da Saúde e atual presidente do Centro Internacional de Longevidade (ILC-Br), Alexander Kalache. O gerontologista acrescenta que "o idoso de 2050 não é uma abstração, ele é o jovem de hoje" e "quem não quiser envelhecer tem de morrer cedo, defendendo a idéia de que o envelhecimento e a longevidade devem ser tratados de forma positiva". ${ }^{1}$

Tal como sugere o relatório "Envelhecimento no Século XXI: Celebração e Desafio" publicado pelo Fundo de População das Nações Unidas em parceria com outras agências da ONU e ONGs, o envelhecimento demográfico é um triunfo do desenvolvimento. Traz, contudo, desafios de toda ordem. Neste sentido, o SecretárioGeral da ONU Ban Ki-moon (UNFPA, 2012), orienta que "é a forma como optamos por tratar dos desafios e maximizar as oportunidades de uma crescente população idosa que determinará se a sociedade colherá os benefícios do 'dividendo da longevidade". ${ }^{2}$ Em outras palavras, o aumento do número de idosos e de anos que viverão deve ser tratado como uma oportunidade, ao contrário de um problema, sobretudo, no que diz respeito à contribuição que eles podem trazer à sociedade se lhes forem oferecidos meios de se manter ativos, seguros e saudáveis.

A despeito do cenário acima apresentado, observa-se que em muitas culturas ainda vigora a imagem da velhice como uma etapa da vida caracterizada apenas por aspectos negativos, perdas e doenças (Beauvoir, 1990; Goldenberg, 2013). Enquanto a infância, a adolescência, a maioridade e a maturidade são fases esperadas, celebradas e atendidas por produtos e serviços diversos e em constante renovação, a velhice é

\footnotetext{
${ }^{1}$ Cfr em http://tedxtalks.ted.com/video/Voc-vai-viver-30-mais-do-que-se

${ }^{2}$ Disponivelem http://www.unfpa.org.br/sumario\%20envelhecimento\%20sec\%20xx.pdf
} 
temida, negada, ignorada e identificada por bengalas, cadeiras de roda, andadores, asilos, hospitais, fraldas geriátricas e pictogramas de indivíduos frágeis e curvados.

As demandas deste público, contudo, vão muito além das necessidades mecânicas inerentes ao avanço da idade e são tão amplas quanto o crescente número de idosos no planeta. Como bem resume Simone de Beauvoir (1990: 345), "a velhice é o que acontece às pessoas que ficam velhas; impossível encerrar essa pluralidade de experiências num conceito, ou mesmo numa noção". Tão ou mais numerosos e heterogêneos do que os públicos infantil, jovem e adulto, os idosos do século XXI não se encerram nos serviços e produtos que a eles vem sendo destinados e impõem urgente extensão e inovação de seu universo material.

\section{GUIA GLOBAL: CIDADE AMIGA DO IDOSOS}

Lado ao envelhecimento e longevidade, observa-se hoje, um intenso processo de urbanização. A previsão é de que em 2030, cerca de três em cada cinco pessoas no mundo viverão em uma cidade (IBGE, Observatório das Metrópoles: 2007). No Brasil, cerca de $80 \%$ da população já vive em cidades, segundo a pesquisa conduzida pelo coordenador do Observatório das Metrópoles, Luiz Cesar de Queiroz Ribeiro.

Diante desta realidade, a Organização Mundial da Saúde desenvolveu o "Guia Global: Cidade Amiga do Idoso" que - como sugere seu título - tem como objetivo fornecer subsídios para a avaliação, promoção e identificação de aspectos que possibilitem, facilitem e melhorem a vida cotidiana da população idosa nas cidades. 0 documento está disponibilizado em vários idiomas e vem sendo utilizado como referência para a formulação de políticas públicas em cidades como Dublin, Nova lorque, São Paulo, e Rio de Janeiro. ${ }^{3}$

Elaborado com base na visão de idosos, cuidadores e prestadores de serviços de 33 cidades de distintas partes do planeta, o documento proporciona novas perspectivas e oportunidades para o campo do design frente ao envelhecimento urbano e será brevemente apresentado nesta sessão.

\subsection{Metodologia}

A metodologia para o desenvolvimento do o "Guia Global: Cidade Amiga do Idoso" foi definida por um grupo de investigadores de diferentes áreas do conhecimento durante workshop realizado em Vancouver, Canadá, em março de 2006. Nessa ocasião foram estabelecidos oito tópicos da vida na cidade: (1) espaços abertos e prédios, (2) transporte, (3) habitação, (4) participação social,(5) respeito e inclusão social, (6) participação cívica e emprego,(7) comunicação e informação; (8) apoio comunitário e serviços de saúde

\footnotetext{
${ }^{3}$.Cfr em http://www.who.int/ageing/GuiaAFCPortuguese.pdf
} 
Foram definidas, também, as cidades participantes do projeto, buscando-se um grupo representativo de todos os continentes; de países desenvolvidos e em desenvolvimento e de variados ambientes urbanos e densidade demográfica. Nas 33 cidades ${ }^{4}$ selecionadas, foram realizados grupos focais formados por idosos de 60 anos ou mais, de classe social baixa e média, em um total de 158 grupos focais, com 1.485 participantes. Foram realizados, também, grupos focais com cuidadores, de modo a se obter dados sobre a realidade de idosos não participantes do estudo em virtude de limitações físicas ou mentais e, ainda, com prestadores de serviços do setor público, privado e voluntário. Os participantes foram questionados sobre as suas experiências, sobre os problemas e as barreiras existentes em suas respectivas cidades e sobre as características de uma cidade amiga do idoso.

\subsection{Principais Resultados}

O "Guia Global: Cidade Amiga do Idoso" teve como principal fonte de informação os idosos que participaram dos grupos focais e foi organizado em torno de oito tópicos da vida na cidade pré-estabelecidos e abaixo resumidos:

\section{Espaços abertos e prédios}

Os espaços exteriores foram altamente valorizados pelos entrevistados, tendo sido observado que ambientes bem planejados contribuem com a mobilidade, a independência e a qualidade de vida dos idosos e aumentam a possibilidade deles envelhecerem em suas próprias casas.

Esta seção ressalta a importância de espaços verdes bem conservados e seguros; de áreas para sentar e descansar; de sinais de trânsito nos cruzamentos; de sinalização padronizada, claramente visível e bem colocada; de ruas e calçadas bem conservadas, livres de obstáculos, niveladas, antiderrapantes e amplas o suficiente para acomodar cadeiras de rodas; de serviços localizados próximos de onde os idosos moram; de banheiros públicos limpos e de fácil acesso a pessoas com diferentes graus de incapacidade.

A beleza natural foi uma das características mencionadas como "amigável ao idoso". Morar próximo ao mar, em cidades como o Rio de janeiro e Cancun, ou próximo ao rio, em cidades como Londres, também foi considerado uma grande vantagem. Em cidades como Himeji, no Japão, os entrevistados valorizaram a paz e a

\footnotetext{
${ }^{4}$ Cidades participantes: (1)Amán, Jordânia; (2) Cancun, México; (3) Dundalk, Irlanda; (4) Genebra, Suíça; (5) Halifax, Canadá; (6) Himeji, Japão; (7) Islamabad, Paquistão; (8) Istambul, Turquia; (9) Kingston e Montego Bay (em conjunto), Jamaica; (10) La Plata, Argentina; (11) Londres, Inglaterra; (12) Mayaguez, Porto Rico; (13) Melbourne, Austrália; (14) Melville, Austrália; (15) Cidade do México, México; (16) Moscou, Rússia; (17) Nairobi, Kenia; (18) Nova Delhi, India; (19) Ponce, Porto Rico; (20) Portage La Prairie, Canadá; (21) Portland, Estados Unidos da América; (22) Oregon, Estados Unidos da América; (23) Rio de Janeiro, Brasil; (24) Região metropolitana de Ruhr, Alemanha; (25) Saanich, Canadá; (26) San José, Costa Rica; (27) Changai, China; (28) Sherbrooke, Canadá; (29) Tókio, Japão; (30) Trípoli, Líbano; (31) Tuymazy, Rússia; (32) Udaipur, Índia; y (33) Udine, Itália.
} 


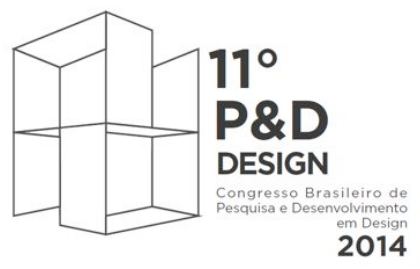

Gramado - RS

De 30 de setembro a 2 de outubro de 2014

tranqüilidade de seus ambientes e em Xangai e Melbourne, as áreas externas para sentar e descansar.

A sensação de segurança foi identificada como um dos aspectos que mais afeta a vontade dos idosos de saírem à rua, e consequentemente, sua independência, saúde física, integração social e bem-estar emocional.

Outra barreira identificada em algumas cidades, como Londres e Tóquio, foi o desaparecimento de pequenas lojas de bairro, fato que implica não somente na necessidade de se deslocar distâncias maiores para fazer suas compras, como na perda de uma importante fonte de contato social.

\section{Transporte}

A mobilidade e consequentemente o acesso ao comércio, eventos e serviços é um fator chave em uma cidade amigável para o idoso e diretamente relacionado à participação cívica e social e o acesso a serviços comunitários e de saúde.

Dentre os principais pontos mencionados como positivos estão o transporte público de baixo custo, com bom planejamento e freqüência de rotas; serviços de veículos amigáveis especializados para pessoas impossibilitadas de usar o transporte público; assentos destinados aos maiores de 60 anos; gentileza dos passageiros e motoristas; segurança e comodidade. Dentre os apontados como barreiras estão as condições precárias das estações e a falta de atenção dos motoristas e de informações sobre horários e rotas.

Em contraponto, foram considerados amigáveis os serviços de táxi, que em alguns países oferecem preço diferenciado aos idosos.

Os motoristas idosos relataram, também, que quando dirigem se deparam com a falta de paciência dos outros motoristas e poucos lugares de estacionamento, o que muitas vezes os impedem de usar o próprio carro como meio de transporte.

\section{Moradia}

A moradia e os serviços de suporte, que permitem aos idosos envelhecer com conforto e segurança na comunidade a que pertencem foram considerados "universalmente valorizados".

Neste sentido, as casas dos idosos devem ser seguras e acessíveis, com espaços adaptados e com áreas de fácil mobilidade. Devem, ainda, ter a capacidade de ser modificadas para atender novas necessidades, a qualquer momento e por um preço justo. Devem, também, ser bem localizadas e perto de lojas, transportes, edifícios públicos e centros que promovam atividades e entretenimento. Os mais velhos devem ter acesso a serviços em casa (limpeza, jardinagem, cuidados pessoais, compras) e, também, o direito a serviços básicos (água, luz, gás, telefone) por um valor reduzido.

A manutenção da casa foi identificada como um grande obstáculo para alguns idosos. Alguns levantaram a dificuldade de arcar com os custos dos consertos. Outros se queixaram da dificuldade de localizar profissionais para realizá-los. Outros demonstraram preocupação quanto ao fato de receber estranhos em suas casas. 
Foi ressaltado o importante papel dos funcionários de moradias coletivas, como zeladores e faxineiros, para os serviços de manutenção em particular e o bem estar dos idosos em geral. Foi ressaltada, também, a importância da prestação de serviços em domicílio. Muitos idosos demonstraram apego às suas casas e desejo de continuar a morar onde sempre moraram e declararam preferir receber ajuda em casa do que ter que se mudar. Morar perto de uma área em que haja serviços, comércio e prédios públicos também foi considerado uma característica amigável ao idoso.

\section{Participação Social}

Participar de eventos, ter grupos de amigos e conviver com os familiares são atividades importantes para o processo de envelhecimento saudável e que favorecem a autonomia, a autoestima e o fortalecimento de vínculos afetivos.

Para que essa participação ocorra é importante oferecer espaços amplos, segurança e acessibilidade. Promover e divulgar atividades variadas pode atrair idosos com diferentes gostos e incentivar novos relacionamentos. Os idosos mostraram receptividade a oportunidades para socializar com pessoas de diferentes gerações e comunidades e a eventos que promovem esse intercâmbio.

A televisão é considerada um meio de socialização, sobretudo para os idosos com limitações físicas. No entanto, a falta de programas voltados para esse público foi apontada como uma característica negativa.

\section{Respeito e inclusão social}

Os entrevistados relataram perceber comportamentos conflitantes em relação a eles. Ora são tratados com consideração, respeito e carinho, ora como crianças e com impaciência. Dentre os preconceitos relatados está a idéia de que os idosos são inúteis, menos inteligentes, pão-duros e um estorvo, já que consomem grande parte dos recursos públicos. Os idosos doentes ou deficientes são vistos sob uma ótica ainda mais negativa. Entrevistados de algumas cidades relataram que prestadores de serviços e profissionais do comércio são desrespeitosos ou desconsideram as necessidades dos idosos.

Em uma cidade amigável, os serviços prestados são inclusivos, adaptados às limitações dos mais velhos e realizados por pessoas capacitadas, cordiais e respeitosas. Foi ressaltada, mais uma vez, a importância de promover a interação de gerações através de eventos sociais, voluntariado e o trabalho em conjunto, de modo a incluir o idoso na sociedade, valorizando seu conhecimento e experiência de vida.

\section{Participação cívica e emprego}

Ter uma ocupação, um emprego remunerado, ou um trabalho voluntário é um desejo de muitos entrevistados e uma forma de manter-se ativo e preservar conexões sociais. Muitos idosos manifestaram vontade de continuar a trabalhar e alguns efetivamente ainda trabalham. Dentre as vantagens de se continuar a trabalhar foram 


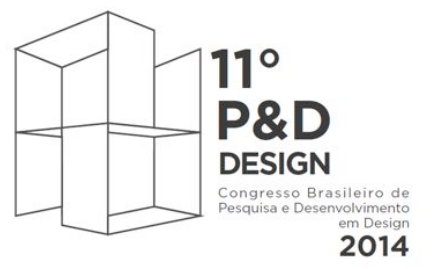

Gramado - RS

De 30 de setembro a 2 de outubro de 2014

levantadas o salário, o combate à idéia de que os idosos são dependentes e a manutenção de relações sociais.

Em alguns países, sobretudo nos mais desenvolvidos, há políticas que promovem e valorizam trabalhadores idosos. Foi observado que os trabalhadores idosos tendem a ser pontuais e há pouco absenteísmo. Dentre as sugestões para criar oportunidades de emprego para os idosos está a criação de incentivos para empregadores que contratam idosos e programas de emprego patrocinado pelo governo, formação de parcerias público-privadas e a contratação de idosos para trabalhar no setor público.

Outra questão levantada nessa seção foi o investimento em habilidades e treinamento para os idosos. Constatou-se que a formação profissional thes dá mais confiança para realizar alguns trabalhos.

Benefícios para obtenção de financiamento e apoio para autônomos, também foram mencionados como fatores de incentivo à participação cívica.

\section{Comunicação e informação}

As cidades necessitam de ampla divulgação de informações. Os entrevistados concordaram que é vital para o envelhecimento ativo ter conhecimento sobre eventos e informações práticas para administrar suas vidas e atender suas necessidades pessoais. Muitos entrevistados expressaram sentir medo de não receber informações e de ficar a margem dos acontecimentos. Houve também preocupação em se obter informações relevantes no tempo certo em cidades de diferentes graus de desenvolvimento. Observou-se, também, que em algumas cidades desenvolvidas há excesso de informações, e as relevantes podem passar despercebidas.

Os entrevistados afirmaram apreciar as tecnologias de informação, mas ressaltaram que os equipamentos eletrônicos poderiam ter uma linguagem mais simples, com letras e números grandes. O acesso a computadores e à Internet em locais públicos, gratuitamente ou mediante pagamento de um valor simbólico é considerado uma característica amigável pelos idosos. Sistemas eletrônicos e de respostas automáticas devem fornecer instruções claras e explícitas, bem como a opção de falar com alguém a qualquer momento.

Observou-se que o sistema "boca-a-boca" é o meio de comunicação preferido dos idosos, pois permite a interação com o informante. O rádio, por sua vez, foi apontado como uma fonte de informação muito popular, sobretudo os programas abertos à participação de ouvintes. A dimensão interpessoal da comunicação é muito importante e estar envolvido na comunidade é uma maneira eficiente de se manter informado. A comunicação amigável ao idoso fornece informações relevantes, regularmente, por meio de canais informais e em lugares onde eles normalmente se reúnem ou ocasiões sociais criadas com este propósito. Pode se dar, também, por meio de "informantes-chave" como profissionais de saúde, assistentes sociais e prestadores de serviços como cabelereiros, carteiros, porteiros entre outras fontes informais de informação. 


\section{Apoio comunitário e serviços de saúde}

Serviços de saúde com preços acessíveis e qualidade é um desejo comum entre os idosos. Os entrevistados concordaram que as unidades de saúde deveriam ser de fácil acesso e possuir maior variedade de tratamentos.

A falta de programas de prevenção a doenças, de espaços para receber idosos que não podem mais viver sozinhos, de serviços de cuidados em casa foram reclamações recorrentes entre os participantes do projeto.

A indiferença, desrespeito, descaso e tratamento do idoso como um estorvo por parte dos prestadores de serviço foi uma queixa comum. O treinamento e sensibilização destes profissionais estão entre as sugestões para melhorar o atendimento e as atitudes com os idosos.

\section{PERSPECTIVAS DO DESIGN EMOCIONAL PARA A PROMOÇÃO DO ENVELHECIMENTO ATIVO}

Tomando como base as orientações do "Guia Global: Cidade Amiga do Idoso" e estudo sobre vertentes, métodos e referencial teórico do design emocional ${ }^{5}$ (Ceccon, 2009; Santos, 2010; Damazio, 2013) foram elaboradas algumas possibilidades de atuação do design em prol do envelhecimento ativo, abaixo resumidos e ilustrados com exemplos.

Design \& Autonomia: engloba ações, produtos e serviços que promovem a autonomia, a independência e a segurança dos idosos.

Um exemplo de produto com foco na promoção da autonomia é o Google Accessibility view. Percebendo que o estado deteriorado das calçadas nas principais cidades do Brasil é um obstáculo, o Google está mapeando as calçadas das cidades e criando uma street view do ponto de vista de cadeirantes. O novo serviço contará com a colaboração de todos, cadeirantes ou não, que utilizarão tags para marcar os pontos críticos das cidades em tempo real. A partir dessas tags, o Google Maps será capaz de determinar as melhores rotas a pé. Todos os que tiverem alguma limitação para se locomover, idosos ou não, poderão escolher as melhores rotas para transitarem pela cidade. $^{6}$

\footnotetext{
5(1) Design e Cidadania; (2) Design \& Bem Estar; (3) Design \& sociabilidade, (4) Design e Autoestima; (5) Design \& Humor; (6) Design e Identidade.

${ }^{6} \mathrm{Cfr}$ em http://www.youtube.com/watch?v=004L1/pbuu8
} 

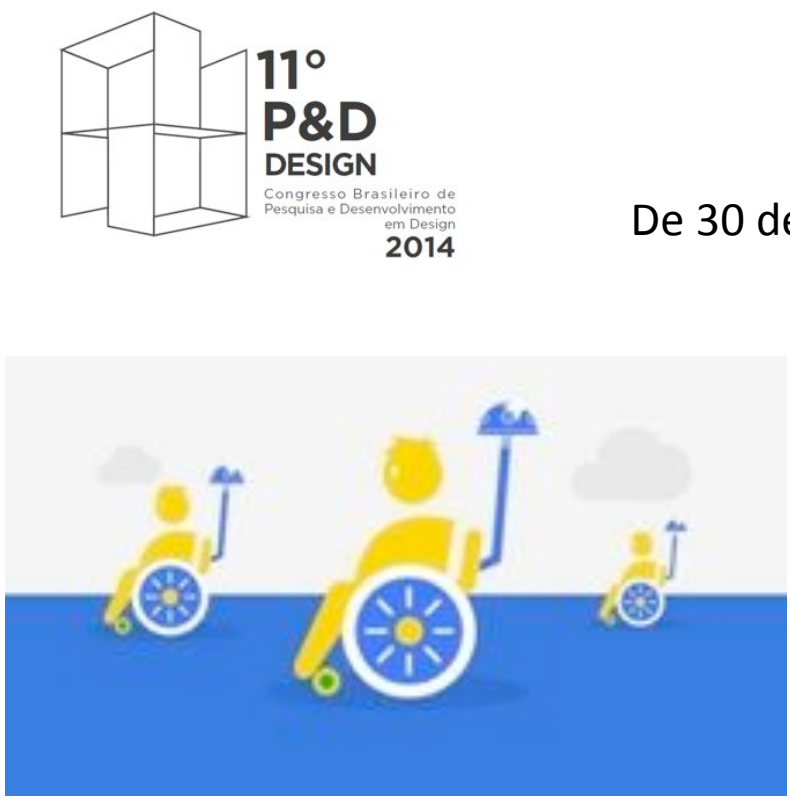

Figure 1: ilustração do vídeo de divulgação do Google Accessibility view

Design \& Sociabilidade: inclui ações, produtos e serviços que estimulam a participação social, que promovem a convivência intergeracional, que fortalecem vínculos sociais e propiciam novas amizades.

Um exemplo de serviço com foco na promoção da sociabilidade é o Speaking Exchange $^{7}$, criado pela rede de escolas de idiomas CNA. Esse projeto possibilita conversas, através de videochat, entre estudantes brasileiros que querem aprimorar o inglês e idosos americanos que querem socializar e diminuir a solidão. $O$ diálogo começa com perguntas sugeridas pelo CNA e é enriquecido pelo surgimento de novos assuntos e interesse mútuo e pela criação espontânea de vínculos afetivos entre os alunos e seus interlocutores idosos. A conversa é gravada para posterior avaliação dos professores do desempenho dos alunos.

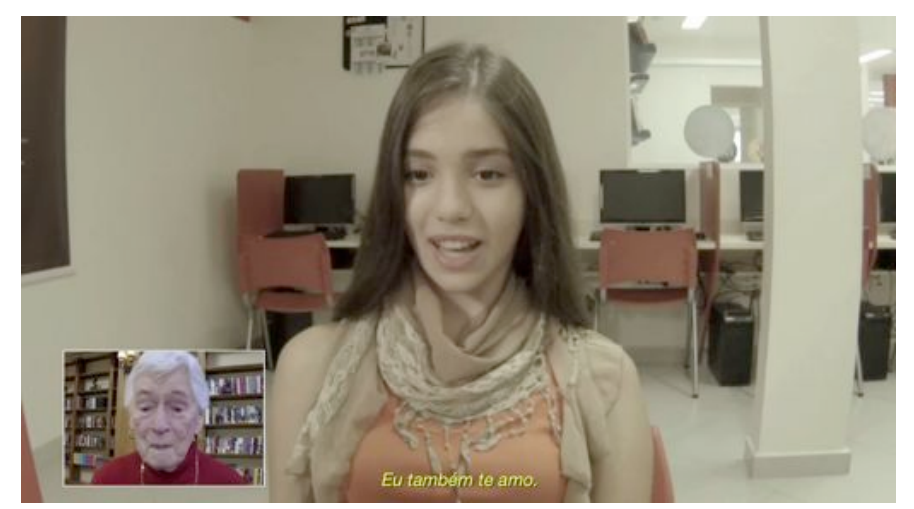

Figure 2: Tela de videochat entre uma aluna do CNA e uma idosa americana.

Design \& Auto estima: envolve ações, produtos e serviços que valorizam os idosos e colaboram para mudar o estigma em torno da velhice.

Um exemplo de produto que tem como foco promover a auto estima é o Calendário criado pelo Asilo Contilia em Essen, na Alemanha, com imagens de seus moradores, recriando cenas famosas e emblemáticas do cinema. O Calendário Asilo Contilia

\footnotetext{
${ }^{7}$ Cfr em http://cna.com.br/speakingexchange/
} 


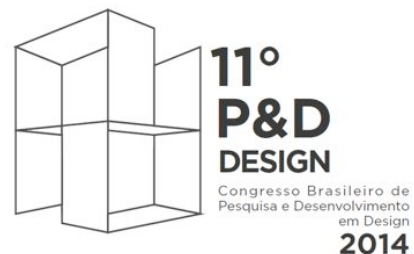

Gramado - RS

De 30 de setembro a 2 de outubro de 2014

ganhou repercussão internacional, promovendo uma visão de que em qualquer idade é possível ser livre, manter o espírito jovem e ter alegria de viver. ${ }^{8}$

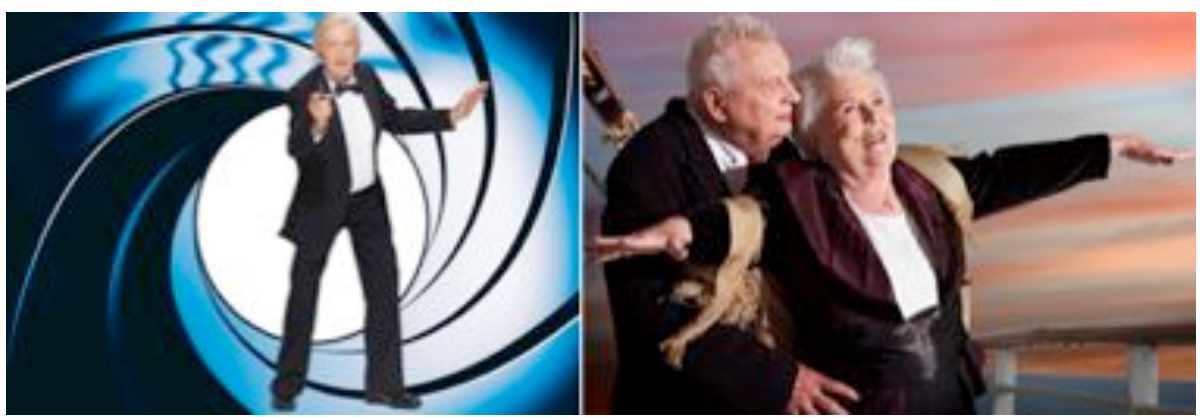

Figura 2: Imagens reproduzidas do Calendário Asilo Contilia

Design \& Engajamento social: envolve ações, produtos e serviços que valorizam e criam oportunidades de trabalho remunerado e voluntário para idosos.

Um exemplo de serviço com foco no engajamento social é o Coroando, projeto desenvolvido por alunas do curso de design da PUC-Rio para promover a troca de experiências entre jovens e idosos no âmbito da escola. Nesse serviço, os idosos tem um papel ativo na educação dos mais jovens a partir de palestras em que relatam as suas experiências de vida e conhecimento sobre determinado tema abordado no programa escolar. Ele é composto por dois veículos: cartazes e site. Os cartazes servem como meio de divulgação dentro das escolas e ponte para os alunos levarem a ideia para seus avós. O site por sua vez, traz informações sobre o projeto e os conteúdos abordados em sala de aula e possibilita o cadastramento dos idosos interessados em participar.

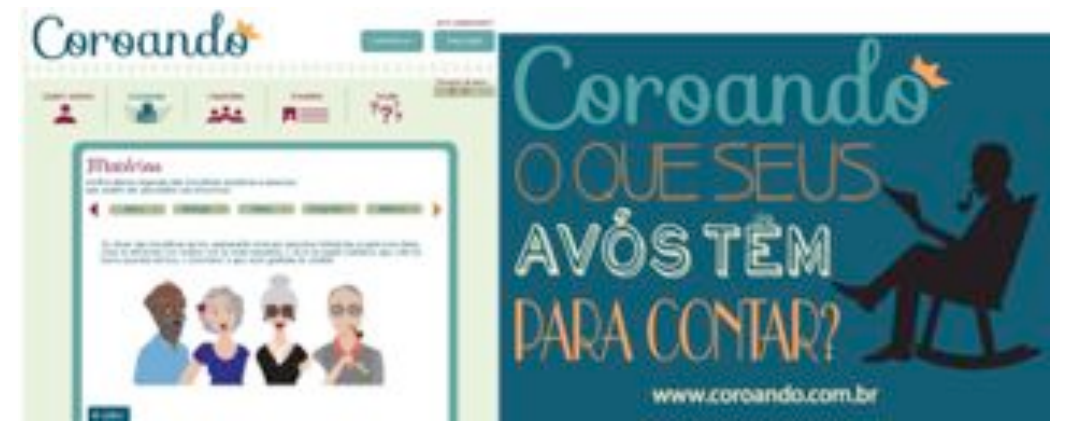

Figure 3: tela do site e cartaz de divulgação do projeto Coroando.

Design \& Bem-estar: está relacionado a produtos e serviços que promovem o bemestar físico, mental ou espiritual, e que incentivam a prática de uma vida mais saudável.

Um exemplo de serviço direcionado à promoção do bem estar do idoso é o TeleHelp, um serviço de teleassistência que funciona através de um aparelho instalado na

\footnotetext{
${ }^{8} \mathrm{Cfr}$ em http://www.buzzfeed.com/ryanhatesthis/a-german-retirement-community-did-a-calendarwhere-seniors-a
} 
residência do idoso e permite que ele, com um único toque, solicite ajuda em casos de emergência. O usuário também pode carregar o botão de emergência sem fio e à prova d'água consigo em forma de colar ou pulseira. Caso o idoso necessite de ajuda, ele pressiona qualquer um dos botões para avisar a uma central de atendimento $24 \mathrm{~h}$ que, por sua vez, comunicará o ocorrido a pessoas pré-selecionadas pelo idoso (familiares, amigos ou vizinhos) e também a profissionais especializados. Esse serviço já é utilizado por milhares de pessoas em mais de 19 países e tem contribuído para uma independência saudável e segura de muitos idosos. ${ }^{9}$

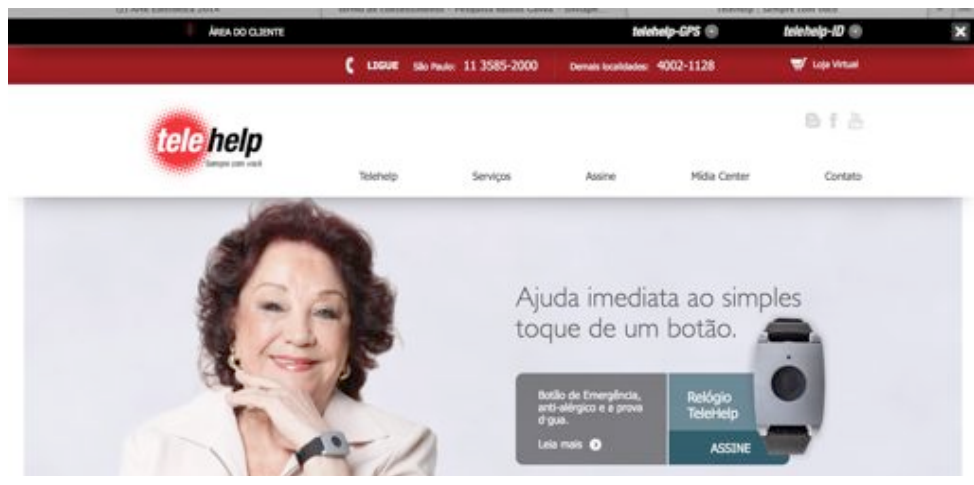

Figure 4:Tela do site TeleHelp.

\section{CONCLUSÃO}

Estamos envelhecendo e vivendo cada vez mais.

O Brasil, hoje, encontra-se entre os seis países com mais idosos do mundo e o Rio de Janeiro é o estado com maior número proporcional de idosos no país. Na cidade do Rio de Janeiro, em cada 10 de seus moradores, um tem mais de 60 anos (IBGE, 2011) $)^{10}$.

Em um cenário cuja tendência é o aumento da população idosa, promover o envelhecimento ativo é uma das abordagens mais eficientes para alcançar a prosperidade e qualidade de vida.

Neste sentido, é vital e urgente que o Design concentre esforços para a construção de um universo mais atento à população que envelhece e aos benefícios da sociedade de viver mais e melhor.

\section{REFERÊNCIAS}

BEAUVOIR, Simone. A Velhice. Rio de Janeiro: Nova Fronteira, 1990.

\footnotetext{
${ }^{9}$ Cfr em http://telehelp.com.br/

${ }^{10}$. Cfr em http://bvsms.saude.gov.br/bvs/folder/10006003219.pdf
} 


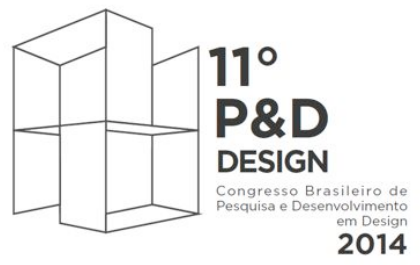

Gramado - RS

De 30 de setembro a 2 de outubro de 2014

CECCON, Marília. Design Emocional: contribuindo para uma nova forma de projetar. Relatório PIBIC - CNPq, 2009. Disponível em: http://www.pucrio.br/pibic/relatorio_resumo2009/relatorio/ctch/art/marilia.pdf

DAMAZIO, Vera. Design, memória, emoção: uma investigação para o projeto de produtos memoráveis. Cadernos de Estudos Avançados em Design: Design e Emoção. Disponível em http://www.tcdesign.uemg.br/pdf/Design_Emocao.pdf

DAMAZIO, V. M. ; CECCON, M. ; QUEZADA, G. D. ; PALHEIROS, L. . Diseño, Consumo y la Guía Global de las Ciudades Amigables con los Mayores.. In: 5to Congreso Internacional de Diseño MX Design Conference 2013 Consumo y Consumismo, 2013, Mexico. MX Design Conference 2013 Proceedings. México: Universidad Iberoamericana, 2013.

Envelhecimento ativo: uma política de saúde/ Organização Mundial da Saúde. Brasília: Organização Pan-Americana da Saúde, 2005.

Envelhecimento no Século XXI: Celebração e Desafio. Fundo de população das Nações Unidas: Nova York. HelpAge Internacional: Londres, 2012.

Guia Global: Cidade Amiga do Idosos/ Organização Mundial da Saúde. Brasília: Organização Pan-Americana daSaúde, 2007.

NERI, Anita Liberalesso (Org.) Idosos no Brasil: vivências, desafios e expectativas na terceiraidade. São Paulo: Ed. Fundação Perseu Abramo, 2007.

RIBEIRO, L. C. de Q. Metrópoles, reforma urbana e desenvolvimento nacional. In: RIBEIRO, L. C. de Q. LAGO, L. As Metrópoles e a Questão Social Brasileira. Rio de Janeiro: Editora Revan, 2007. P. 21 - 47

SANTOS, Alan Bruno. Acervo de Design Emocional: perspectivas, produtos, referencias teórica e método. Relatório PIBIC - CNPq, 2010. Disponível em: http://www.puc-rio.br/pibic/relatorio_resumo2010/relatorios/ctch/art/ARTAlan\%20Bruno\%20dos\%20Santos.pdf 